\title{
Dietary patterns of 24-month old children and associated nutrient intakes and body weight status
}

\author{
Á. Hennessy ${ }^{1,2}$, C. ní Chaoimh ${ }^{1,2}$, E.K. McCarthy ${ }^{1,2}$, E. Ryan ${ }^{1}$, C. Shanahan ${ }^{1}$ and M. Kiely ${ }^{1,2}$ \\ ${ }^{1}$ Cork Centre for Vitamin D and Nutrition Research, School of Food and Nutritional Sciences and \\ ${ }^{2}$ Irish Centre for Fetal and Neonatal Translational Research (INFANT), University College Cork, Cork, Ireland
}

Dietary pattern analysis is a useful method to describe the whole diet and evaluate associations with health outcomes and can complement traditional methodologies which use individual foods or nutrients ${ }^{(1)}$. There are few dietary pattern studies in young children.

We aimed to identify the dietary patterns of young children living in Ireland, and investigate associations with body weight status and nutrient intakes and status. Cross-sectional food consumption data of 24-month old children participating in the Cork BASELINE Birth Cohort Study ${ }^{(2)}$ were collected using a 2-day weighed food record $(\mathrm{n}=468)$. K-means clustering was conducted to identify predominant dietary patterns on the basis of the \% contribution of food groups to total energy intake (\%TE). Body weight status $^{(3)}$, adequacy of nutrient intake and biomarkers of vitamin D and iron status were compared across the dietary pattern groups.

Four dietary pattern clusters were derived from this analysis, two of which differed principally by the type and volume of milk a child consumed, namely "Cows' milk" [median (IQR): 495 (178) ml/d; 32 \%TE] and "Formula" [median (IQR): 368 (193) ml/d; 23 \% TE]. A "Traditional" pattern, characterised by higher intakes of wholemeal breads, butter and fat spreads, fresh meat and fruit, with lower intakes of processed meat, and a "Convenience" pattern, characterised by higher intakes of sweets, confectionary and cakes $(15 \% \mathrm{TE})$, processed meat, convenience foods (pizza, spaghetti hoops, instant noodles) and lower intakes of fresh meat, were identified.

Overall, $7 \%$ of children were classified as obese $\left(>98^{\text {th }}\right.$ centile); however, no significant associations between dietary patterns and body weight $(p=0 \cdot 121)$, height $(p=0 \cdot 327)$ or body weight status $\left(>98^{\text {th }}\right.$ centile: $p=0 \cdot 328$; BMI z-score: $\left.p=0 \cdot 170\right)$ at 24 months were observed.

\begin{tabular}{|c|c|c|c|c|c|c|}
\hline & & $\begin{array}{c}\text { Cows' milk } \\
(\mathrm{n}=160)\end{array}$ & $\begin{array}{c}\text { Formula } \\
(\mathrm{n}=55)\end{array}$ & $\begin{array}{l}\text { Convenience } \\
(n=116)\end{array}$ & $\begin{array}{c}\text { Traditional } \\
(\mathrm{n}=137)\end{array}$ & $P$ \\
\hline & Requirement & 71.9 & 80.1 & ? & 05.6 & $<0.001$ \\
\hline Total carbohydrate & $45-60 \% \mathrm{TE}^{(5)}$ & $90 \cdot 6$ & $80 \cdot 0$ & $74 \cdot 1$ & 83.2 & $\begin{array}{r}<0.001 \\
0.004\end{array}$ \\
\hline Free sugar & $<10 \% \mathrm{TE}^{(6)}$ & 61.9 & $52 \cdot 7$ & 31.0 & $54 \cdot 7$ & $<0.001$ \\
\hline Dietary fibre & $>2 \mathrm{~g} / \mathrm{MJ}^{(5)}$ & $56 \cdot 9$ & $65 \cdot 5$ & $65 \cdot 5$ & $85 \cdot 5$ & $<0.001$ \\
\hline
\end{tabular}

Compliance with EFSA total fat ${ }^{(4)}$ and dietary fibre ${ }^{(5)}$ DRVs was lowest in the "Cows' milk" group and the "Convenience" group had lower compliance with the WHO DRV for free sugars ${ }^{(6)}$. All groups meet the EFSA protein DRV ${ }^{(7)}$. Due to fortification, the "Formula" group had higher intakes of vitamin D $(8.2 \mathrm{vs} 2.0 \mu \mathrm{g} / \mathrm{d})$, iron $(10.4 \mathrm{vs} 6.3 \mathrm{mg} / \mathrm{d})$, vitamin C $(109 \mathrm{vs} 71 \mathrm{mg} / \mathrm{d})$ and zinc $(6.7 \mathrm{vs} 5.1 \mathrm{mg} / \mathrm{d})$ than the other groups, and had higher serum 25 -hydroxyvitamin D concentrations $(76.7 \mathrm{vs} 61.9 \mathrm{nmol} / \mathrm{L})$ and iron stores, as determined by CRP-corrected serum ferritin concentrations $(26.4 \mathrm{vs} 23 \cdot 7 \mu \mathrm{g} / \mathrm{L})$.

In conclusion, few foods differentiated the children in this study, highlighting the homogeneity in dietary patterns in toddlers. This analysis, in a highly educated and motivated cohort, emphasises deficits in the toddler diet and the urgent need for evidence-based dietary recommendations for appropriate feeding in young children.

1. Smithers LG, Golley RK, Brazionis L et al. (2011) Nutr Revs 69, 449-467.

2. O'Donovan SM, Murray DM, Hourihane JO'B et al. (2015) Int J Epi 44, 764-775.

3. Wright CM, Williams AF, Elliman D et al. (2010) BMJ 340, c1140.

4. European Food Safety Authority (2010) EFSA Journal 8(1461), 1-107.

5. European Food Safety Authority (2010) EFSA Journal 8(1462), 1-77.

6. WHO (2015) Guideline: Sugars intake for adults and children. www.who.int

7. European Food Safety Authority (2010) EFSA Journal 10(2), 1-66. 